\title{
O consumo nos consome* : a produção dos sujeitos contemporâneos e a escola
}

\section{Consuming which consumes us: producing contemporary subjects and the school}

\author{
Janaina Souza NEULS ${ }^{1}$ \\ Mariangela $\mathrm{MOMO}^{2}$ \\ Viviane Castro CAMOZZATO ${ }^{3}$
}

RESUMO: Que modos de ser sujeito a sociedade contemporânea vem produzindo, ao colocar determinados corpos, como um objeto a ser incansavelmente buscado e desejado? Cremos que essa é uma questão candente para a área educacional, porque é propulsora de modos de crianças, jovens e adultos se relacionarem consigo mesmos e com os outros. Por acreditarmos que somos construídos nas tramas da cultura é que nos propomos, neste estudo, a discutir questões que estão relacionadas aos contemporâneos jeitos da sociedade ocidental pautar modos de existência através da glorificação do corpo, marcas de gênero, consumo de si mesmo. Com base em autoras como Beatriz Sarlo, Denise Sant'Anna, Ieda Tucherman, entre outras/os, refletimos sobre as transformações ocorridas nas relações entre os sujeitos e seus corpos; relações que tendem, cada vez mais, a transformar o corpo num espetáculo. Para tanto, tencionamos posicionamentos que estamos adotando através de análises da mídia impressa e eletrônica, assim como acontecimentos que observamos em escolas públicas de Porto Alegre/ RS.

Palavras-chave: corpo, sujeito, mídia, consumo, escola

\footnotetext{
* Essa parte do título faz alusão ao livro El consumo me consume de Tomás Moulian. (Cf. ref. bibl).

${ }^{1}$ Mestre em Educação pela Universidade Federal do Rio Grande do Sul - UFRGS. E-mail: janaina_neuls@yahoo.com.br

${ }^{2}$ Pedagoga. Especialista em Educação Infantil pela Universidade Federal do Rio Grande do Sul - UFRGS. E-mail: marimomo@brturbo.com.br

${ }^{3}$ Pedagoga. Especialista em Educação Infantil pela Universidade Federal do Rio Grande do Sul - UFRGS. E-mail: vipoa2002@yahoo.com.br

Olhar de professor, Ponta Grossa, 8(2): 179-187, 2005.
} 
ABSTRACT: What are the ways of being a subject that contemporary society has been producing, when putting forth certain bodies as an object to be tirelessly sought after and desired? We believe this to be a passionate matter in the educational area because it is the driving force behind children, youths and adults in their elationships. Believing that we are construed in the culture web, we propose, in this study, to discuss matters which are related to the way in which contemporary western society glorifies the body, brands, being the consumer of itself. Based on authors such as Beatriz Sarlo, Denise Sant'Anna, Ieda Tucherman, among many others, we have reflected on the changes occurred in the relationship between the subjects and their bodies, which tend to, more and more, turn the body into a spectacle. For this, we are adopting a position through analyses of the media, printed and electronic, as well as events which we have observed in state schools in Porto Alegre/RS.

Key words: body, subject, media, consume, school

Neste estudo o conhecimento do corpo e o próprio corpo são entendidos como produzidos histórica e culturalmente. Não negamos a materialidade do corpo e os elementos biológicos que o constituem; no entanto, consideramos que ele não é apenas algo dado ou determinado pela natureza. Se pensarmos em termos do que pode ou não causar nojo e ânsias de vômito em uma pessoa, por exemplo, veremos que a causa muda de cultura para cultura. $\mathrm{O}$ que para nós pode ser nojento e causar uma reação notadamente física (vômito) pode, para outras pessoas, de outras culturas, ser absolutamente normal e não provocar qualquer tipo de reação. Aprendemos, por meio da cultura, o que repugnar, o que comer, o que vestir, como andar, como marcar a alegria ou a tristeza em nossos rostos, entre outras atitudes ou ações.

Além disso, consideramos que o corpo é produzido pelo seu tempo, adquirindo suas marcas. Assim, na Idade Média cristã o manto da castidade 'cobria as suas vergonhas; nas cortes européias (XVII e XVIII); o corpo trazia sinais da aristocracia e da riqueza (perucas, jóias, etc.); e no final do século XX e início do século XXI temos a indústria da moda e seu império do efêmero intervindo sobre os corpos. (TUCHERMAN, 1999). Eé sobre os tempos atuais que voltamos nosso olhar para falar de corpo. Um tempo em que aprendemos a ser sujeitos, a ser corpo, não mais apenas através de instituições como Igreja, Família e Escola, mas através da mídia e do consumo, que fazem parte de nossa vida cotidiana. Assim, diariamente somos bombardeados por discursos e imagens de corpos, na mídia impressa e eletrônica, que funcionam como pedagogias culturais, produzem sentidos e nos ensinam modos de sentirmos nossos corpos. Autores/as que investigam as relações entre mídia 
e educação, como Fischer (1997, p.61), afirmam que a mídia não pode ser vista apenas “" [...] como veiculadora, mas também como produtora de saberes e formas especializadas de comunicar e de produzir sujeitos, assumindo nesse sentido uma função nitidamente pedagógica".

Assim, nos inquieta perguntar: que importância estamos dando aos nossos corpos? Como estão sendo representados? Quais marcas de gênero inscrevem? Que modos de ser sujeito podem (ou não) ser criados pelas imagens e seus sentidos? Como um corpo é espetacularizado? Inspiradas em autoras como Beatriz Sarlo, Denise Sant'Anna, Ieda Tucherman, entre outras/os, estamos pensando nas transformações ocorridas nas relações entre os sujeitos e seus corpos; relações que tendem, cada vez mais, a transformar o corpo num espetáculo. Para tanto, analisamos imagens da mídia impressa eletrônica, principalmente de crianças e jovens, que funcionam como pedagogias culturais. Ou seja, a mídia - e muitos outros artefatos culturais - promovem ensinamentos relativos às identidades e às subjetividades dos sujeitos contemporâneos. Colocamos em evidência e analisamos também acontecimentos relativos ao corpo que têm povoado as escolas públicas de Porto Alegre, onde pesquisamos e/ou trabalhamos.

Segundo Sarlo (2000), vivemos um tempo em que impera, a partir do próprio corpo, o mito da beleza e da ju- ventude (como se beleza e juventude fossem sinônimos de saúde). Aprendemos o que é ser belo e ser jovem através da mídia e do consumo, que produzem a beleza e a juventude através das formas de representação. Breves análises de imagens postas em circulação, na mídia impressa e eletrônica, nos mostram corpos. No caso de corpos femininos, magros, altos, brancos, sem rugas, cicatrizes ou celulites, dentes brancos, cabelos lisos e claros, sexualizados, seios e nádegas volumosos, etc. Se forem corpos masculinos, são musculosos, altos, brancos, caixa torácica larga, etc. Com relação ao corpo, cabe destacar que diariamente são lançados produtos e procedimentos que pretendem nele intervir para, por um lado, adiar a velhice dos adultos, por outro, antecipar a juventude das crianças. Tais produtos e procedimentos pretendem realizar no corpo uma metamorfose programada, prevista, desejada, produzida e imposta. A modificação corporal é imposta pelos padrões de beleza e juventude produzidos nas sociedades ocidentais contemporâneas, fazendo com que as pessoas não meçam esforços para atingilos. Alguns alunos de escolas públicas, por não ter condição financeira para colocar um piercing ou fazer uma tatuagem, utilizam procedimentos doloridos e arriscados na incessante busca em satisfazer os desejos relativos ao corpo. Por exemplo: usam uma agulha de costura, aquecendo-a e imergindo sua ponta em tinta de caneta para desenhar (tatuar) sob a pele; 
usam um brinco ou um clips para perfurar a cartilagem do nariz e colocar o tão almejado piercings.

Diferentemente do passado, quando o corpo era considerado como algo dado por Deus, atualmente os corpos são planejados a partir dos desejos expressos em uma tela de computador (vale lembrar o ilustre exemplo do cantor pop norte-americano Michael Jackson). Tais desejos são construídos para que sonhemos com objetos e procedimentos que possam transformar nossos corpos. Vivemos em um mundo em que as novidades de consumo relativas ao corpo são praticamente diárias. Produtos e procedimentos são imediatamente substituídos pelas próximas novidades, também efêmeras, causando a sensação de que nunca estamos suficientemente atualizados quando o assunto é corpo. O apelo midiático e comercial institui modas relativas ao corpo que vão da ponta do dedão ao último fio de cabelo, aproveitando todo o espaço comercial corpo. $\mathrm{Na}$ contemporaneidade, o corpo tem sido alvo de inúmeros investimentos, tornando-se passível de várias intervenções, ou seja, modificações que o transformam, marcam, diferenciam. A moda, a estética, cirurgias, adereços e tatuagens são algumas das possíveis intervenções que demonstram o quanto o corpo vem sendo invadido, ressignificado e investigado. Crianças ainda muito pequenas demonstram preocupações com seus corpos talvez inimagináveis ou inaceitáveis em outros tempos, como por exemplo, o desejo de depilar as pernas. Podemos encontrar nas ruas indivíduos comuns com corpos espetacularizados. É a própria sociedade do espetáculo e das visibilidades.

Vivemos em um mundo onde o espetáculo pode ser ambulante e configurar-se no próprio corpo através de tatuagens, piercings e cabelos multicoloridos. Talvez possamos dizer que um dos elementos que constitui a sociedade do espetáculo é o público, pois um espetáculo requer espectadores para ser visto, notado, apreciado, percebido. E parece-nos que as escolas têm funcionado como o local privilegiado para a exibição de corposespetáculo - de crianças, jovens e até mesmo adultos - porque nela concentra-se alguma espécie de público. Para nós, que trabalhamos em escolas públicas de Porto Alegre - e é desde este contexto que estamos falando -, cenas como a relatada a seguir são freqüentes: uma menina chega à escola, mostrando suas unhas para as colegas. Todas querem pegar na sua mão e sentar ao seu lado. Dizem que ela está linda e perguntam quem pintou suas unhas. Mostra para as professoras e para as/os outras/os funcionárias/os da escola, todos elogiam suas unhas. Na hora do intervalo, mostra para a professora da outra turma e, novamente, recebe elogios. Essa menina queria público para apreciar o espetáculo, já que suas unhas estão pintadas praticamente da mesma cor de um anúncio que diz: Esmal- 
te fluorescente. Brilha no escuro e na luz negra.

Um esmalte fluorescente que brilha no escuro e na luz negra é um esmalte que pretende, no mínimo, chamar atenção, pois é para ser visto mesmo no escuro, proporcionar espetáculo. Tatuagens que vêm junto com chicletes ou compradas avulso e utilizadas pelas crianças também promovem espectadores. Todos querem ver o Batmann; ou, então, uma camisa de Homem-Aranha muito colorida e exibida em movimentos que imitam o personagem do filme pode ter o mesmo efeito. Diariamente, em uma turma de crianças em torno dos quatro anos, de uma escola de periferia em que uma das autoras deste texto trabalha, as crianças vêm para a escola com novas tatuagens, brinquedos e até figuras adesivas de personagens como Meninas Superpoderosas, Barbie, dentre outras, e mostram para os colegas e para a professora. Parece-nos que se não houver espectadores para observar esses objetos, praticamente colados a seus corpos como se dele fizessem parte, não teria sentido trazê-los para a escola.

Produz-se o próprio corpo em relação ao que os outros irão ver, esperam ou não ver, segundo os padrões de exigência produzidos pela mídia e pelo consumo. Talvez possamos dizer que um desses padrões de exigência diz respeito ao gênero. Produz-se gêneros para os corpos através das marcas que nele se inscrevem. Assim como, ao longo do tempo, o corpo vai adquirindo marcas como as de fertilidade, de velhice, de situações específicas como doenças ou acidentes, nele também se inscrevem marcas de gênero. Observamos que nas conversas de nossos alunos sobre filmes, desenhos e programas assistidos na tevê, as crianças freqüentemente demonstram seus desejos por brinquedos veiculados pela mídia. Não apenas as meninas se interessam em adquirir sandálias e mochilas de personagens que aparecem, principalmente, na tela da tevê. Os meninos também mostram esse interesse. Quando foi lançada a sandália do personagem Senninha (inspirado no piloto de Fórmula 1, Ayrton Senna), em uma de nossas turmas vários meninos foram para a escola orgulhosos, mostrando a nova aquisição que vinha com uma mochila de brinde. Nas propagandas desse produto, os meninos apareciam em situações de aventura, sugerindo velocidade, agilidade e esportividade para quem estivesse utilizando tal calçado.

Como já afirmamos anteriormente, em um mundo de visibilidades o espetáculo se configura no próprio corpo. Os corpos de crianças e jovens estampam personagens que parecem ser direcionados para grupos de meninas e meninos. Meninas mostram acessórios, roupas e calçados da Barbie, da Hello Kitty, Meninas Superpoderosas, com cores que ressaltam o rosa e o brilho. São imagens que valorizam uma feminilidade ligada ao cultivo da beleza. Santos (1997, 
p. 96) comenta que alguns/algumas bonecos/as (que incluem a Barbie, mas não se limitam a ela) produzem nos corpos o que é considerado bonito: magreza, olhos claros, cabelos loiros e longos e pele branca. Esse mesmo autor argumenta que

[...] as bonecas são somente a ponta de um processo de representação que se iniciou na mídia televisiva e que alcança, com suas construções de sonhos, papéis, de lugares na sociedade, de modos de vestir, de estilos de vida, etc., um enorme público atento a consumir de uma forma ou de outra tais representações (SANTOS, 1997, p. 95).

Gostaríamos de destacar a crescente proliferação de imagens, na mídia impressa e eletrônica, que se articulam na produção dos significados sobre o gênero. Contudo, a mídia majoritariamente representa apenas o corpo como masculino ou como feminino, como se não existissem outras possibilidades entre esses dois pólos. Essas discussões nos fazem pensar que, ao consumirmos representações que constroem os modos de nos posicionarmos no mundo, tendemos, nesse processo, a consumir a nós mesmos.

\section{O INESCAPÁVEL CONSUMO DE SI MESMO}

Que modos de ser sujeito a sociedade contemporânea vem produzindo ao colocar determinados corpos como um objeto a ser incansavelmente buscado e desejado? Ora, a questão levantada, longe de ter uma resposta única, nos leva a discutir características do tempo presente que, inescapavelmente, nos atingem. Por exemplo: nos mais variados espaços sociais, as discussões estabelecidas giram em torno de uma preocupação consigo mesmo. Ou seja, os sujeitos contemporâneos são assolados por anseios que envolvem as suas vidas individuais através de aspectos relativos a emprego, estudo, relacionamentos amorosos, assim como as questões ligadas ao corpo e aos modos de torná-lo mais desejado, sexy, bonito, jovial, produtivo... Essas são preocupações que parecem balizar as relações do sujeito consigo mesmo e com os demais [em detrimento das questões de ordem mais coletiva]. Com isso, os laços de união e afeto giram em torno de uma, ao menos suposta, superficialidade que invade todos os recantos de nossa existência, já que há sempre algo novo, ou um outro modo de parecer ser, a ser perseguido por sujeitos individuais.

A fabricação constante de novos desejos a serem infinitamente buscados nos leva a pensar na banalização do privado, onde nossos desejos e práticas mais íntimos passam a ser expostos e visibilizados, seja na grande mídia, seja através da exposição diária nos espaços em que circulamos, nos quais conversamos sobre os mais variados temas. A naturalidade com que algumas alunas pedem, em voz 
alta, licença para ir ao banheiro trocar o absorvente interno, assim como as vidas narradas nas viagens de ônibus em que há vários ouvintes sendo platéia, demonstram o esmaecimento entre o que seria da ordem pública e o que seria da privada. "O que parece estar em jogo é uma redefinição da esfera pública como um palco em que dramas privados são encenados, publicamente expostos e publicamente assistidos" (BAUMAN, 2003, p.83). Assim sendo, no mundo das visibilidades, em que você só parece fazer sentido, existir, se está exposto, o corpo se torna um slogan e passaporte para a felicidade. Portanto, não é mais a alma que precisa ser trabalhada, melhorada, mas o corpo que, por ser visto, passa a sofrer intervenções para ser melhor apreciado. Essa é uma tendência contemporânea, como ressalta Sant'Anna (2002, p. 106): “[...] transformar todas as partes do corpo em imagens de marca e num marketing privilegiado do eu. Por conseguinte, o desejo de investir nas imagens corporais torna-se proporcional à vontade de criar para si um corpo inteiramente pronto para ser filmado, fotografado, em suma, visto e admirado."

Assim, num mundo que se transmuta rapidamente e onde o exaurimento do presente, indeterminação, efemeridade, narcisismo, individualismo, consumo e descartabilidade, entre outras características, tornam-se cada vez mais as balizadoras de uma rede de relações e afetos, fica mais fácil compreender, conhecendo essa conjuntura, que ser sujeito nestes tempos é uma experiência bem distinta de ter sido sujeito em décadas anteriores. Enquanto humanos, aliás, não nos comportamos uniformemente no tempo e vivemos em temporalidades disjuntivas, que proporcionam a inscrição das marcas da multiplicidade em nós. Com isso, queremos dizer que os significados presentes na época em que nos situamos nos constroem como um tipo específico de sujeito, uma vez que esses ensinamentos - que operam nas redes sociais e que entram, também, nas escolas - nos subjetivam, nos fazem realizar uma volta sobre nós mesmos produzindo, assim, um efetivo e produtivo direcionamento da nossa vida interior num processo que transforma, instante a instante, os nossos "eus".

Podemos pensar, ainda, nas seguintes perguntas direcionadas às mulheres [meninas-crianças, jovens, adultas]: Você está magra? Está bonita? Você é desejável? É sexy? Você se cuida? Essas são questões cotidianamente pautadas por um desejo de colocar todos, e cada um de nós, dentro de certas normas, a fim de que, enredados nessas tramas, nos submetamos a estar em conformidade com os contemporâneos parâmetros de normalidade que são fabricados. Esse nosso enredamento nos habilitará para o consumo, pois assim poderemos saber o que, quando e como consumir para nos mantermos dentro das fronteiras. A submissão aos enuncia- 
dos expostos são os nossos novos e modernos remédios para a realização da nossa auto-transformação. Afinal, será que é a alma que importa nestes tempos? Tudo indica que para muitas pessoas não; para elas o que importa é o corpo, pois cuidar desse novo "templo" "[...] significaria, portanto, o melhor meio de cuidar de si mesmo, de afirmar a própria personalidade e de se sentir feliz." (SANT'ANNA, 2002, p.99).

Para finalizar, frisamos que as questões levantadas são importantes para mostrar que não consumimos apenas os objetos em sua materialidade. $\mathrm{Ou}$ seja, não somos apenas aficcionados por bolsas, sapatos, jóias, roupas de marca..., mas aficcionados pelos significados associados a esses objetos. Ter um tênis da marca Nike, Reebok, Adidas, ou algum outro desse tipo, nos faz pertencer a um grupo em que determinados significados são associados a quem tem tal objeto. Esse possuir coloca a pessoa em questão num certo patamar, pois ela está mostrando aos demais que está assumindo uma identidade diferente daquele que não tem como comprar ou conseguir um tênis socialmente valorizado. Não é à toa, portanto, que esse objeto desperta tanta paixão atualmente. Pelo domínio dos significados associados a um tênis de marca, algumas pessoas são capazes de matar e morrer. Em fevereiro de 2005, por exemplo, na cidade de Porto Alegre, Brasil, foi motivo de debate a morte de um jovem de dezessete anos que acabou sendo baleado após a tentativa de assalto em que o principal objeto a ser roubado era o seu tênis de marca.

Engana-se quem pensa, portanto, que há somente objetos materiais a serem consumidos, produtos que movimentam capitalísticamente o mundo. Mais do que a moderna separação entre "[...] um sujeito consumidor e um objeto consumido [...]" (HOMEM, 2003, p.03), notamos que nos atuais tempos o próprio sujeito torna-se um objeto de consumo, aperfeiçoando-se continuamente e respondendo afirmativamente aos apelos e desejos que são, infinitamente, criados pela sociedade do espetáculo e do consumo. Nesse sentido, vale a pena deixar ressoar, infinitamente, a pergunta: como estamos nos transformando no que somos?

\section{REFERÊNCIAS}

BAUMAN, Z. Modernidade líquida. Trad. Plínio Dentzien. Rio de Janeiro: Jorge Zahar, 2001. p. 64-106.

FISCHER, R. M. B. O estatuto pedagógico da mídia: questões de análise. Educação \& Realidade, Porto Alegre, v. 22, n. 2, p. 59-80, jul./dez. 1997.

HOMEM, M. L. Entre próteses e prozacs. O sujeito contemporâneo imerso na descartabilidade da sociedade de consumo. Estados Gerais da Psicanálise: rede dos estados gerais da psicanálise. Disponível em: <http://estadosgerais.org/ m u ndi a 1 r j/d ow n lo a d / 4_Homem_135161003_port.pdf $>$. Acesso em: 24 nov. 2003. 
MOULIAN, Tomás. El consumo me consume. Santiago de Chile: Libros Del Ciudadano, 1998.

SANT'ANNA, D. B. Transformações do corpo: controle de si e uso dos prazeres. In: RAGO, M.; ORLANDI, L. B. L.; VEIGA-NETO, A. (Orgs.). Imagens de Foucault e Deleuze: ressonâncias nietzschianas. Rio de Janeiro: DP\&A, 2002. p.99 - 110 .

SARLO, B. Cenas da vida pós-moderna. Intelectuais, arte e vídeo-cultura na Argentina. Trad. Sérgio Alcides. 2. ed. Rio de Janeiro: Ed. UFRJ, 2000.

SANTOS, L. H. S. Um pretinho mais clarinho... ou dos discursos que se dobram nos corpos produzindo o que somos. Educação \& Realidade, Porto Alegre, v. 22, n. 2, p. 81-115, jul./dez. 1997.

TUCHERMAN, I. III. Monstros, freaks e cyborgs - o outro do corpo e o corpo do outro. In: TUCHERMAN, I. Breve história do corpo e seus monstros. Lisboa: Veja, 1999. p. 95 - 176.

Encaminhado em: 03/10/05

Aceito em: 17/11/05 